\title{
FLIPI Score Greater than or Equal to 3, High Risk
}

National Cancer Institute

\section{Source}

National Cancer Institute. FLIPI Score Greater than or Equal to 3, High Risk. NCI

Thesaurus. Code C136968.

A score indicating that a patient has 3 or more risk factors associated with follicular lymphoma and is considered in the high risk group. 